\title{
J-pouch versus Roux-en-Y reconstruction after gastrectomy: functional assessment and quality of life (randomized trial)
}

This article was published in the following Dove Press journal:

OncoTargets and Therapy

16 December 2016

Number of times this article has been viewed

\author{
Pavel Zonča ${ }^{1,2}$ \\ Tomáš Malý ${ }^{3}$ \\ Peter Ihnát ${ }^{1,2}$ \\ Matus Peteja ${ }^{1,2}$ \\ Otakar Kraft ${ }^{4}$ \\ Kamil Kuca ${ }^{2,5}$ \\ 'Department of Surgery, University \\ Hospital Ostrava, ${ }^{2}$ Department of \\ Surgical Studies, Faculty of Medicine, \\ University of Ostrava, Ostrava, \\ ${ }^{3}$ Department of Surgery, University \\ Hospital Olomouc, Olomouc, \\ ${ }^{4}$ Department of Nuclear Medicine, \\ University Hospital Ostrava, Ostrava, \\ ${ }^{5}$ Biomedical Research Center, \\ University Hospital Hradec Kralove, \\ Hradec Kralove, Czech Republic
}

Purpose: The aim of this study was to evaluate the quality of life and functional emptying of J-pouch versus Roux-en-Y reconstruction after total gastrectomy for malignancy.

Methods: This study was designed as a prospective, nonblinded, randomized, parallel clinical trial (Trial Number: MN Ostrava, 200604). With informed consent, patients undergoing gastrectomy for malignancy were randomized to J-pouch or Roux-en-Y reconstruction. The time taken for a test semisolid meal labeled with ${ }^{99 \mathrm{~m}} \mathrm{Tc}$-sulfur colloid to exit the reconstructed parts was measured by dynamic scintigraphy 1 year after resection. Quality of life was measured using the Eypasch questionnaire at the same time as functional emptying assessment. This trial was investigator-initiated.

Results: In all, 72 patients were included into the study. The time taken for the test meal to exit the postgastrectomy reconstruction was $16.5 \pm 10.0$ minutes (mean \pm standard deviation) in the Roux-en-Y group and $89.4 \pm 37.8$ minutes in the "J-pouch" group; the difference was statistically significant $(P<0.001)$. Emptying of the J-pouch appeared to be a linear decreasing function compared to the exponential pattern seen in the Roux-en-Y group. The quality of life measurement showed scores of $106 \pm 18.8$ points (mean \pm standard deviation) in the Roux-en-Y group compared to $122 \pm 22.5$ points in the J-pouch group; the difference was statistically significant $(P=0.0016)$. There were no important adverse events.

Conclusion: After total gastrectomy, a J-pouch reconstruction empties more slowly and is associated with higher quality of life compared to Roux-en-Y reconstruction. Whether these two observations have a direct causative link remains unanswered.

Keywords: gastrectomy, J-pouch, Roux-en-Y, gastric emptying, quality of life, dynamic scintigraphy

\section{Introduction}

Total gastrectomy for cancer requires anatomical reconstruction to restore continuity of the alimentary tract. Postgastrectomy syndrome, arising due to the absence of the stomach, can have a serious impact on an individual's nutritional status and can result in an impaired quality of life. ${ }^{1-3}$ Although these symptoms often improve with time, a significant proportion of patients with gastric cancer do not have a prolonged survival. Therefore, it is important that efforts should be focused on ensuring the best quality of remaining life. ${ }^{1,3}$

The surgeon can reduce the impact of stomach absence by creating a gastric substitute made from the remaining intestine, which may incorporate a reservoir and may or may not maintain passage through the duodenum. It is possible that a reservoir as well as the passage through the duodenum improves the quality of life..$^{4-7}$
Correspondence: Pavel Zonča;

Kamil Kuca

Department of Surgery, University Hospital Ostrava, 17 Listopadu 1790 , Ostrava 708 52, Czech Republic Tel +42069603289166 Email pavel.zonca@fno.cz; kamil.kuca@fnhk.cz 
The aim of this study was to compare the two methods of reconstruction after total gastrectomy with specific regard to the time taken for a test meal to exit from the reconstructed segment and on quality of life. J-pouch represents postgastrectomy reconstruction with reservoir and preserved transduodenal passage. Roux-en- $Y$ is reconstruction without reservoir and without maintained passage through the duodenum. These two methods have been chosen because of the preservation of the transduodenal passage in the J-pouch reconstruction, which presents a very important factor in our opinion. The comparison with Roux-en-Y has been performed because it is considered to be a gold standard of reconstruction after gastrectomy. According to the literature, this standard reconstruction with $40 \mathrm{~cm}$ of alimentary limb is comparable with J-pouch as a reservoir. Our hypothesis was that longer emptying times lead to fewer agastric symptoms and better quality of life. Several studies focused on pouch reconstruction after gastrectomy have been performed, including meta-analysis. However, the relation between evacuation after reconstruction and quality of life is not so clear.

\section{Materials and methods}

This study was designed as a prospective, nonblinded, randomized, parallel clinical trial with institutional ethical committee approval (Trial Number: MN Ostrava, 200604) (April 4, 2006) and fully informed consent, patients undergoing total gastrectomy were invited to participate in the study. Prior to surgery, patients were randomized (block randomization) to two different types of reconstruction using a Roux-en-Y or J-pouch (intervention) (Figure 1). The participants were recruited in short blocks ensuring that half of the participants within each block were allocated in each trial arm. The primary outcome metrics of this study, measured 1 year after gastrectomy, were: 1) time taken for a test semisolid meal labeled with ${ }^{99 \mathrm{~m}} \mathrm{Tc}$-sulfur colloid to be emptied from the reconstructed segment, and 2) quality of life according to the Eypasch score. Participants were selected according to the inclusion criteria: age $\geq 18$ and $<85$ years, indication for gastrectomy without peritoneal carcinomatosis, stage I-III disease or lymphoma, without contraindication to surgery in general anesthesia (ASA 1-3), and patient's consent. Exclusion criteria were contraindication to radionuclide scanning and recurrent cancer within the year after gastrectomy and immunosuppression therapy. The primary endpoint was the length of evacuation in the upper part of the gastrointestinal tract after reconstruction. In each group, a minimum of 17 patients was required in order to detect a difference in emptying time from 30 to 40 minutes with $80 \%$ power and significance set at $5 \%$.

Emptying times of reconstruction segments were measured by dynamic scintigraphy 1 year after gastrectomy. The examination was performed in the morning after an overnight fasting according to consensus recommendations of the
A

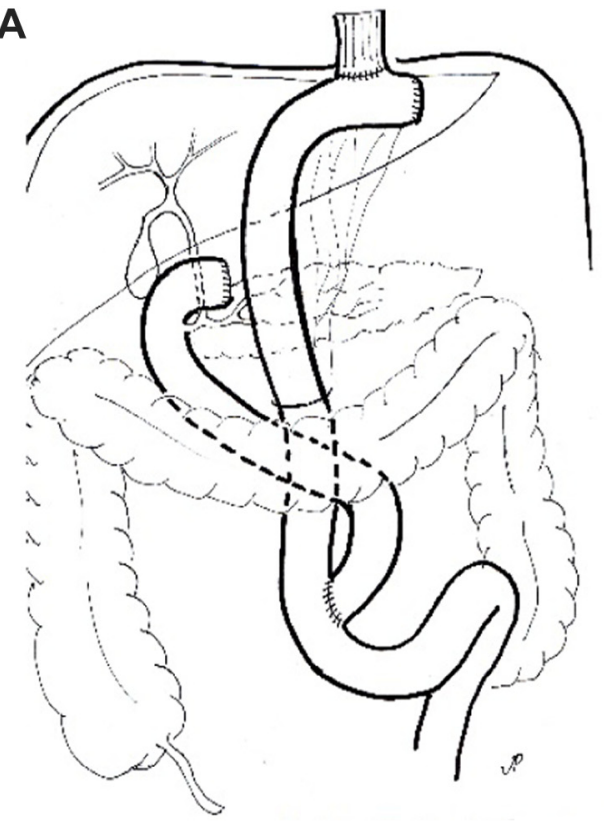

B

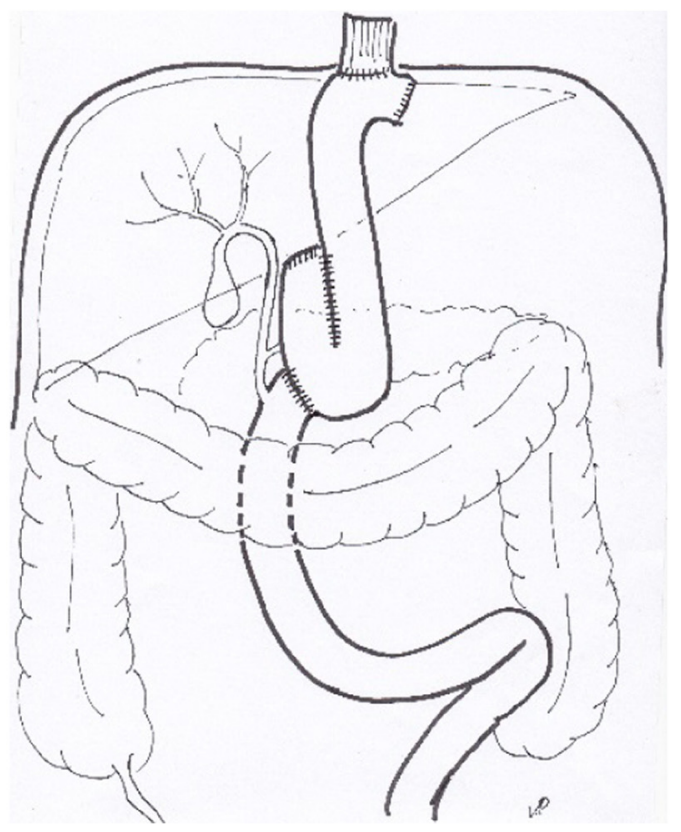

Figure I Scheme of postgastrectomy reconstructions.

Notes: (A) Roux-en-Y reconstruction and (B) “J-pouch" reconstruction. 
American Neurogastroenterology and Motility Society and the Society of Nuclear Medicine. ${ }^{8,9}$ Patients ingested a test semisolid meal consisting of $200 \mathrm{~mL}$ rice labeled with ${ }^{99 \mathrm{~m}} \mathrm{Tc}$ sulfur colloid over 5 minutes in a sitting position. A gamma camera was used to detect emissions over the whole abdomen continuously for 90 minutes after the meal in a recumbent position, and then at two further time points -2 and 3 hours postingestion. ${ }^{9-12}$

Gamma camera images were acquired using a $140 \mathrm{keV}$ ${ }^{99 m}$ Tc photopeak with a $20 \%$ window. A low-energy, allpurpose collimator was used to maximize the count rate. Images were acquired in a $128 \times 128$ word mode matrix. Continuous data recording at a framing rate of 30-60 seconds per image was performed. After correction for ${ }^{99 \mathrm{~m}} \mathrm{Tc}$ physical decay, the geometric mean activity counts were determined at each imaging time. The percentage of gastric retention at a specific time point was calculated with respect to the immediate postingestion value at the zero time point. $8,10,12$

The secondary endpoints were the incidence of heartburn, dumping syndrome, and early feeling of the fullness after eating.

Quality of life was measured on a single occasion (1 year after gastrectomy) using the modified Eypasch questionnaire, which inquires about many symptoms associated with gastrointestinal malfunctions, such as belching, pyrosis, swallowing disorders, dumping syndrome, food intake, character, and frequency of defecation. This questionnaire includes 36 items scored from 0 (worst) to 4 (best). The sum of the item scores yields an overall quality of life score (maximum $=144$ ). Eypasch questionnaire is detailed and includes questions dealing with gastrointestinal symptoms, physical condition, emotions, social integration, and effects of treatment. ${ }^{13}$

Results of postgastrectomy reconstruction emptying times and quality of life measurement were analyzed and tested by means of descriptive statistics. As emptying times did not follow the normal distribution, comparison between groups was made by the Mann-Whitney $U$-test. Quality of life was normally distributed and so a Student's $t$-test was used. Emptying times were correlated with quality of life using Spearman's rank correlation. SPSS version 15 was used for all statistical analysis (SPSS Inc., Chicago, IL, USA).

The patients were followed up at 3-month intervals after the surgery.

\section{Results}

In total, 81 patients were recruited into the study and gave consent to randomization, from 2007 till 2014. The CONSORT diagram, presented in Figure 2, shows the flow through the trial. In all, 39 patients were allocated to receive Roux-en-Y reconstruction and 42 patients were allocated to "J-pouch" reconstruction. Four patients in the Roux-en-Y group and

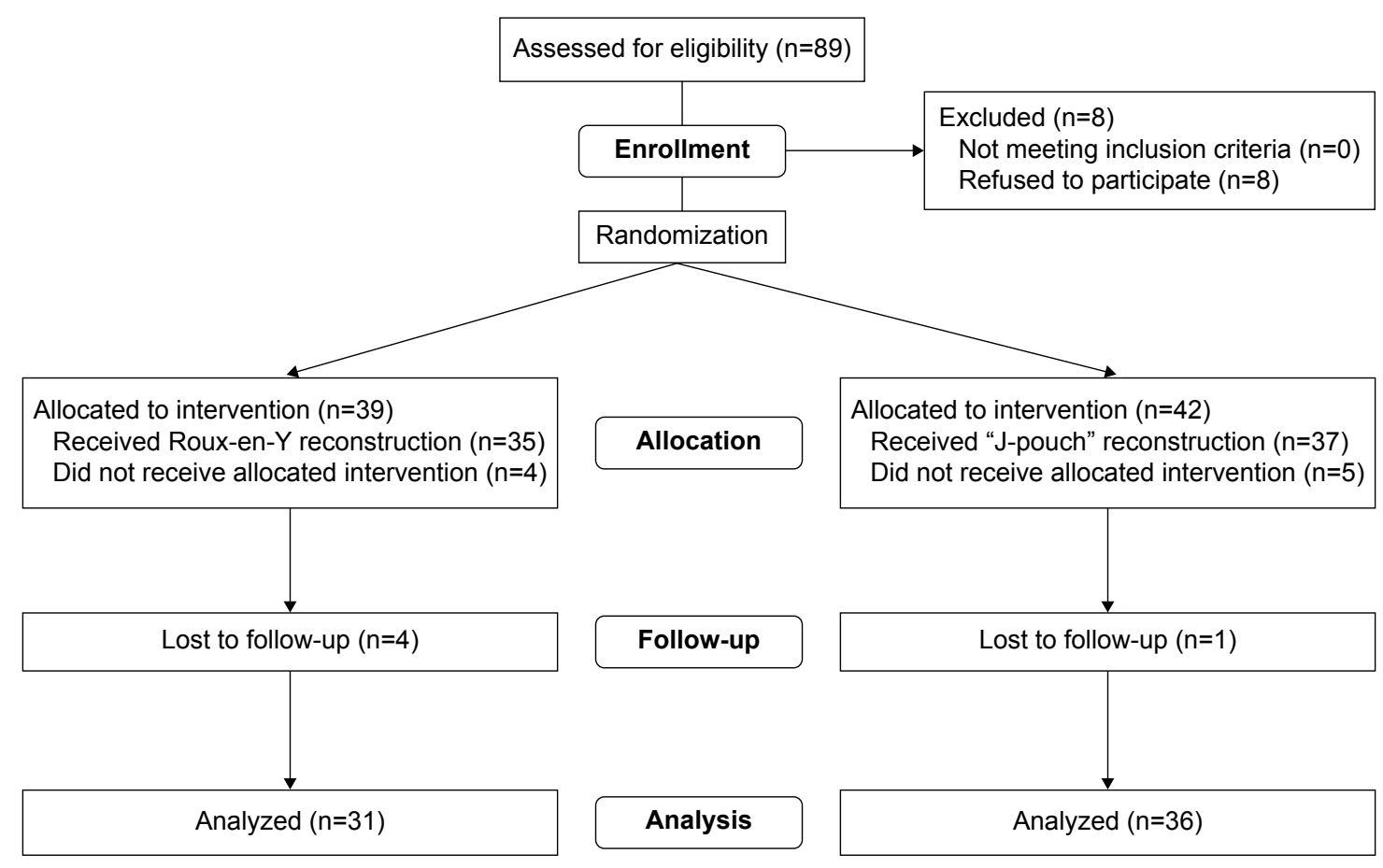

Figure 2 The CONSORT diagram showing flow through the trial. 
five in the J-pouch group did not receive their allocated reconstruction. The reason for not performing gastrectomy and allocated reconstruction in these patients was the intraoperative finding of peritoneal carcinomatosis.

Altogether, 35 patients received Roux-en-Y reconstruction after total gastrectomy. This group consisted of 26 men and nine women with a mean age of 63.5 years. A total of 37 patients received J-pouch reconstruction; there were 23 men and 14 women with a mean age of 62.2 years (Table 1).

All total gastrectomies were performed in the standard way. The average time of surgery was 226.7 minutes in

Table I Age, gender, and cancer stage of all patients included into the trial

\begin{tabular}{|c|c|c|c|c|c|c|}
\hline \multicolumn{4}{|c|}{ “J-pouch" } & \multicolumn{3}{|c|}{ Roux-en-Y } \\
\hline & $\begin{array}{l}\text { Age } \\
\text { (years) }\end{array}$ & Gender & $\begin{array}{l}\text { Stage } \\
\text { (UICC) }\end{array}$ & $\begin{array}{l}\text { Age } \\
\text { (years) }\end{array}$ & Gender & $\begin{array}{l}\text { Stage } \\
\text { (UICC) }\end{array}$ \\
\hline I. & 61 & $\mathrm{~F}$ & I A & 65 & $M$ & II B \\
\hline 2. & 60 & M & III B & 77 & M & I B \\
\hline 3. & 45 & $\mathrm{~F}$ & III B & 80 & M & II B \\
\hline \multirow[t]{2}{*}{4.} & 64 & $\mathrm{~F}$ & Lymphoma & 65 & M & Lymphoma \\
\hline & & & IV A & & & IV A \\
\hline 5. & 69 & $\mathrm{~F}$ & III A & 70 & M & III C \\
\hline 6. & 74 & $\mathrm{~F}$ & II A & 56 & M & III C \\
\hline 7. & 57 & $M$ & III A & 45 & $\mathrm{~F}$ & IB \\
\hline 8. & 45 & M & Lymphoma IV A & 75 & M & II B \\
\hline 9. & 42 & M & I B & 43 & M & I B \\
\hline 10. & 59 & $M$ & III A & 76 & M & II A \\
\hline II. & 64 & $\mathrm{~F}$ & $\| \mathrm{A}$ & 65 & $M$ & III A \\
\hline 12. & 57 & M & III A & 74 & $M$ & III B \\
\hline 13. & 67 & $\mathrm{~F}$ & II B & 51 & M & III C \\
\hline 14. & 45 & M & II A & 55 & M & II B \\
\hline 15. & 73 & $M$ & III C & 51 & $\mathrm{~F}$ & II A \\
\hline 16. & 63 & M & III A & 73 & $M$ & III A \\
\hline 17. & 59 & M & Lymphoma IV A & 60 & M & III A \\
\hline 18. & 68 & M & I A & 68 & M & I B \\
\hline 19. & 45 & M & III A & 48 & M & III B \\
\hline 20. & 66 & $\mathrm{~F}$ & III A & 78 & $\mathrm{~F}$ & III B \\
\hline 21. & 73 & $\mathrm{~F}$ & III A & 67 & M & III A \\
\hline 22. & 62 & M & III B & 71 & $\mathrm{~F}$ & III A \\
\hline 23. & 74 & M & III A & 65 & M & II B \\
\hline 24. & 67 & M & III B & 53 & $\mathrm{~F}$ & III B \\
\hline 25. & 58 & $\mathrm{~F}$ & II B & 49 & M & III A \\
\hline 26. & 81 & M & I B & 68 & M & III A \\
\hline 27. & 68 & $\mathrm{~F}$ & III B & 58 & M & II A \\
\hline 28. & 51 & $M$ & III A & 72 & M & III B \\
\hline 29. & 61 & $\mathrm{~F}$ & II A & 55 & $\mathrm{~F}$ & I B \\
\hline 30. & 73 & $M$ & III B & 68 & M & III A \\
\hline 31. & 69 & M & III A & 61 & $\mathrm{~F}$ & III A \\
\hline 32. & 58 & $M$ & Lymphoma IV A & 74 & $\mathrm{~F}$ & II B \\
\hline 33. & 63 & M & I B & 68 & M & I B \\
\hline 34. & 58 & $\mathrm{~F}$ & III A & 54 & M & $\| \mathrm{A}$ \\
\hline 35. & 54 & $\mathrm{~F}$ & III B & 63 & $\mathrm{~F}$ & III B \\
\hline 36. & 72 & M & II B & & & \\
\hline 37. & 76 & M & III A & & & \\
\hline \multicolumn{7}{|c|}{ Total, $\mathrm{n} \pm \mathrm{SD}$ or ratio } \\
\hline & 62,2 & $23: 14$ & & 63,5 & $26: 9$ & \\
\hline
\end{tabular}

Abbreviation: UICC, Union for International Cancer Control.
Table 2 Selected symptoms occurrence after gastrectomy

\begin{tabular}{lll}
\hline & “J-pouch” & Roux-en-Y \\
\hline Heartburn & 5 & $\mathrm{I}$ \\
Dumping syndrome & $\mathrm{I}$ & 6 \\
Fullness feeling after meal & 5 & 9 \\
\hline
\end{tabular}

the J-pouch group, and 178.1 minutes in the Roux-en-Y group $(P<0.05)$. No patients had a postoperative leak or intestinal obstruction. The 30-day morbidity was $62 \%$ in the J-pouch group and 49\% in the Roux-en-Y group. Hospital stay was 12.4 days in the J-pouch group and 10.7 days in the Roux-en-Y group. Postoperatively, all patients were followed-up in the oncosurgical outpatient clinic. Thirteen patients in the J-pouch group and 17 patients in the Roux-en-Y group received chemotherapy. Four patients in Roux-en-Y group and one patient in the J-pouch group were lost during follow-up. After all, 67 patients were analyzed and assessed 1 year after gastrectomy by means of dynamic scintigraphy and quality of life questionnaire. There were no important adverse events. The following symptoms were separately evaluated: heartburn, dumping syndrome, and fullness feeling after meal (Table 2).

The meal evacuation assessment from postgastrectomy reconstructed segment was done by means of dynamic scintigraphy with ${ }^{99 \mathrm{~m}} \mathrm{Tc}$-sulfur colloid (Table 3; Figure 3). The length of meal evacuation from the reconstructed segment in the group of patients with Roux-en-Y reconstruction was $16.5 \pm 10.0$ minutes (mean \pm standard deviation). The length of meal evacuation from J-pouch was $89.4 \pm 37.8$ minutes. The difference was found to be statistically significant $(P<0.001$, Mann-Whitney $U$-test).

Table 3 QoL and length of evacuation after gastrectomy within both study groups

\begin{tabular}{lll}
\hline $\begin{array}{l}\text { Group of } \\
\text { patients }\end{array}$ & $\begin{array}{l}\text { Length of } \\
\text { evacuation }(\mathbf{m i n})\end{array}$ & QoL \\
\hline "J-pouch" & & \\
$\mathrm{N}$ & 36 & 37 \\
Minimum & 15 & 62 \\
Maximum & 184 & 134 \\
Median & 89.50 & 103.00 \\
Mean & 89.36 & 102.51 \\
SD & 37.782 & 16.588 \\
Roux-en-Y & & \\
N & 31 & 35 \\
Minimum & 3 & 57 \\
Maximum & 43 & 117 \\
Median & 16.00 & 94.00 \\
Mean & 16.45 & 92.57 \\
SD & 9.963 & 14.337 \\
\hline
\end{tabular}

Note: QoL assessed according to Eypasch questionnaire. Abbreviations: QoL, quality of life; SD, standard deviation. 


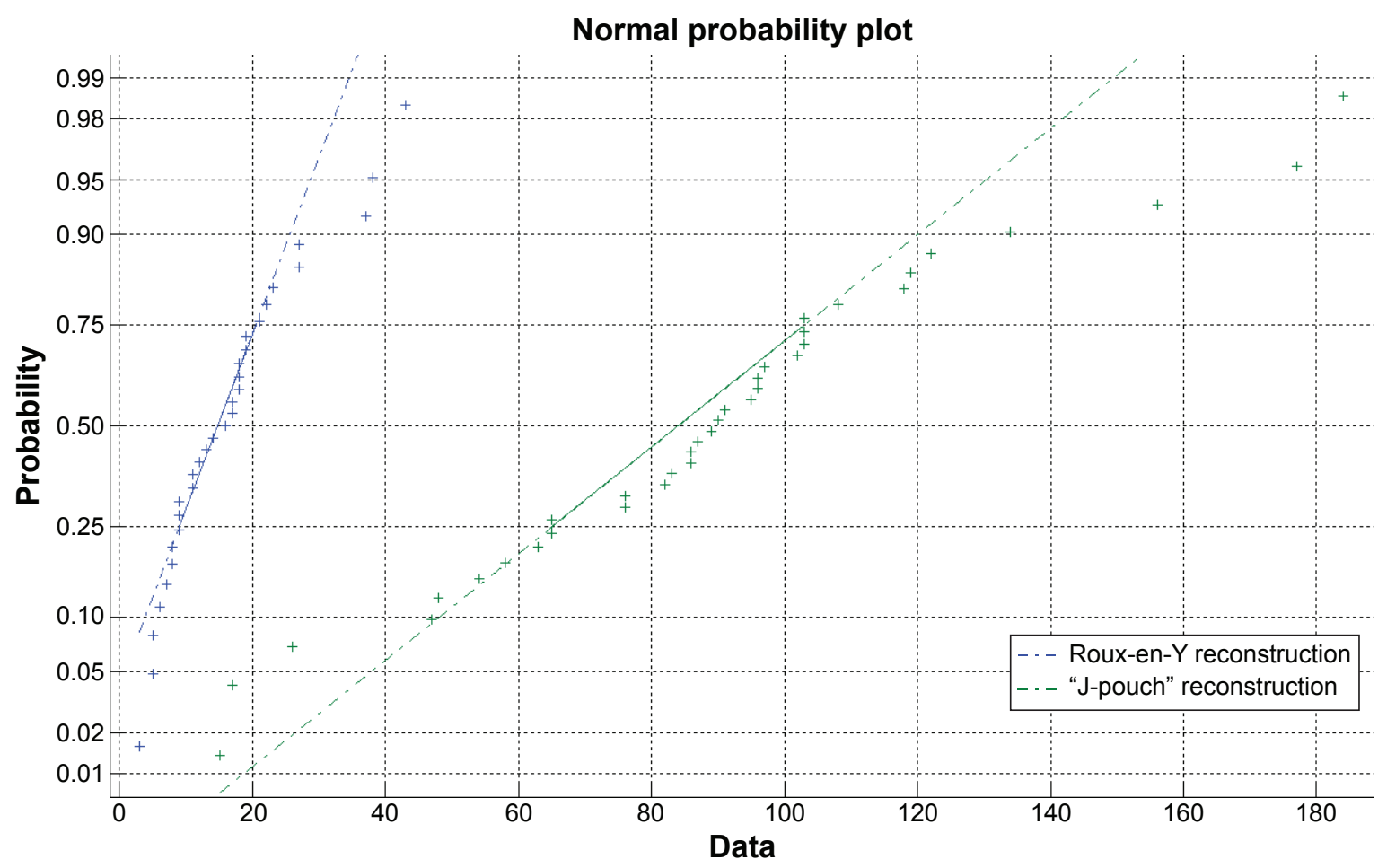

Figure 3 Normal probability plot comparing the distribution of data from evacuation of "J-pouch" and Roux-en-Y reconstruction with normal distribution.

Emptying times of the Roux-en-Y reconstruction showed an exponential distribution (Figure 4A). After test meal ingestion, there was a steep increase of activity counts in the reconstructed segment, but 15 minutes later the radioactivity in the reconstructed segment was almost zero. The ingested test meal proceeded without delay into the small intestine beyond reconstruction. This shape of the emptying curve showed the inability of Roux-en-Y to keep the test meal in a reconstructed segment.

J-pouch emptying appeared to be a linear decreasing function (Figure 4B). Shortly after test meal ingestion, there was a steep increase of activity counts in the J-pouch with very slow gradual emptying. The high level of radioactivity in the J-pouch remained for more than an hour. The ingested test meal was slowly and fluently released into the small intestine beyond the pouch. The shape of the emptying curve showed very good reservoir function of the J-pouch, which indicates almost physiological proceeding of food through the upper gastrointestinal tract.

Quality of life assessment was done by the use of standardized Eypasch questionnaire 1 year after surgery. The achieved quality of life score in the group of patients with Roux-en-Y
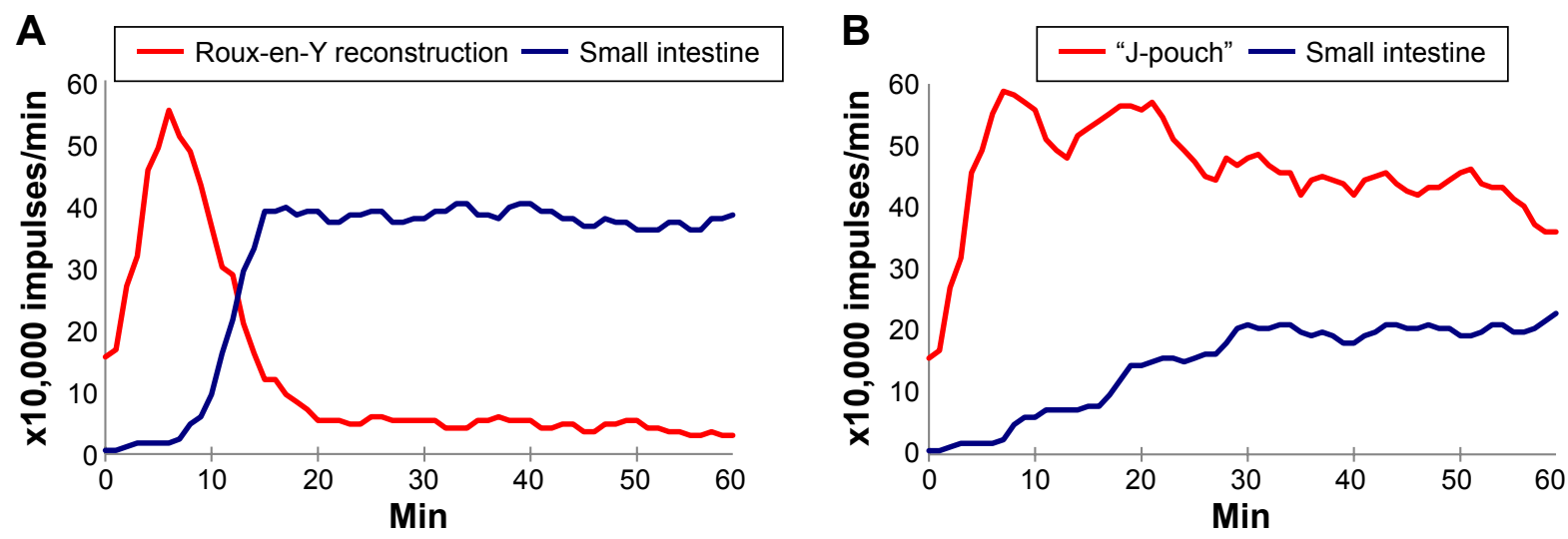

Figure 4 Examples of postgastrectomy reconstruction emptying curves (corrected for physical radioisotopic decay) obtained by dynamic scintigraphy after ingestion of semisolid test meal labeled with ${ }^{99 \mathrm{~m}} \mathrm{Tc}$-sulfur colloid.

Notes: Red curve - radioactivity detected in reconstructed segment; blue curve - radioactivity detected in small intestine beyond reconstruction. (A) Roux-en-Y reconstruction and (B) "J-pouch" reconstruction. 
reconstruction was $106 \pm 18.8$ points (mean \pm standard deviation). Patients with J-pouch reconstruction obtained a quality of life score measuring $122 \pm 22.5$ points. The difference was found to be statistically significant ( $P=0.0016, t$-test). According to these results, patients with J-pouch reconstruction showed a significantly higher quality of life than patients with Roux-en-Y reconstruction.

\section{Discussion}

In this prospective study, we carried out a functional assessment of emptying of a Roux-en-Y reconstruction compared to a J-pouch following total gastrectomy for cancer. Our main finding was a significantly slower emptying of a J-pouch, associated with a higher quality of life. This study was not designed to determine whether there is a direct causative effect of emptying time on patients' quality of life.

Undoubtedly, findings of this study have direct clinical relevance. Postgastrectomy syndrome can be a debilitating result of surgery, and any improvement in surgical technique that impacts on this would be advantageous. There is a growing body of evidence to suggest that the type of reconstruction after total gastrectomy can minimize this problem. ${ }^{1,4,14,15}$

Since Schlatter performed the first successful gastrectomy in $1897,{ }^{16}$ around 80 types of reconstruction have been described. In Europe, the favored postgastrectomy reconstruction is a Roux-en-Y. Haberer et al reported that only $16 \%$ of 62 European clinics perform a J-pouch reconstruction after the total gastrectomy. ${ }^{17}$ Reconstructions may be classified as those in which the duodenal passage is retained or not. Another classification criterion may be the presence of reservoir or pouch component., ${ }^{1,2,18}$

Keeping the passage of food through the duodenum may help to maintain better control of postprandial release of hormones and regulatory peptides. ${ }^{5,19}$ Whether this, or indeed a reservoir component, improves the quality of life remains unclear. But, it seems plausible that intestinal motility of the reconstructed part may play an important role in the quality of life after gastrectomy by preventing dumping and early satiety. ${ }^{4,20,21}$

There are several methods available to assess gastrointestinal motility. The application of radionuclides for gastric emptying measurement was introduced in $1966 .{ }^{22}$ Gastric emptying scintigraphy represents the gold standard for measurement of gastric emptying in clinical practice because it allows physiologic, noninvasive, and quantitative data measurement..$^{8-10,12}$ Using scintigraphy, rapid emptying of a solid meal has been associated with dumping symptoms in patients who undergo reconstruction with Roux-en-Y and jejunal interposition without a pouch. ${ }^{23}$

Postgastrectomy syndrome is a function of more than a simple absence of the stomach. Denervation is an accepted consequence of gastrectomy and may affect motor, exocrine, and endocrine functions of the entire gastrointestinal tract. Disruption of intrinsic neural integrity may result in disordered contractile activity of the reconstruction. ${ }^{17,24,25}$ Sarr and Kelly showed that extrinsic nerves were necessary for postprandial motor activity, and we might therefore assume that extrinsic neural integrity of the reconstructed intestine may be important for postprandial pouch function. ${ }^{26}$

Mochiki et al compared the function of jejunal interposition with or without a pouch after a total gastrectomy for gastric cancer. They confirmed that the jejunal wall of the pouch was capable of contraction at a level similar to normal jejunum 6 months after surgery. However, manometry revealed that the coordinated motor function of the pouch was not apparent until 6 months after surgery. ${ }^{20}$

Tomita et al have shown that motility continues to improve beyond 6 months after the surgery. They studied gastrointestinal hormone and jejunal interdigestive migrating motor complex in patients with or without early dumping syndrome after the gastrectomy with Roux-en-Y reconstruction. An interesting finding of their study was that a new pacemaker is established at the oral side of the resected jejunum that is well established by 9 months after surgery. ${ }^{19}$

Nakane et al have shown that a shorter conduit and wider mesenteric pedicle preserve blood supply and extrinsic neural integrity and lead to better pouch function. ${ }^{21}$ Tsujimoto et al suggest that the optimal jejunal pouch should be relatively short. In their study, a shorter pouch was associated with higher incidence of early dumping symptoms, but also with higher eating capacity per meal and lower postoperative weight loss 24 months after surgery. ${ }^{27}$

In conclusion, the present study has shown that postgastrectomy reconstruction with $\mathrm{J}$-pouch compared to a Roux-en-Y reconstruction results in slower emptying of a test meal and, in addition, an improved quality of life. The weak points of the trial are: a) the overall length of the study with difficulty of recruitment of patients, b) the change of perioperative chemotherapy standards during the study, and c) Eypasch score outcomes affected by subjective factors (as any other quality of life questionnaire). Whether there is a causative link or simply an association has not been unequivocally demonstrated in this study. Although the primary goal of radical gastrectomy must remain oncological cure, 
patients' quality of life after surgery is important and should be included in the overall management decision process.

\section{Acknowledgments}

This work was supported by the long-term development plan of Faculty of Medicine, Ostrava University and University Hradec Kralove. The authors thank Dr J Zapletalova, biomedical statistician for statistical analysis, and Mr Damian J Mole, University of Edinburgh, for comments on the manuscript.

The trial was supported by a grant from Switzerland and through the Swiss Contribution to the enlarged European Union.

\section{Disclosure}

The authors report no conflict of interest in this work.

\section{References}

1. Clark CJ, Thirlby RC, Picozzi V Jr, Schembre DB, Cummings FP, Lin E. Current problems in surgery: gastric cancer. Curr Probl Surg. 2006; 43(8-9):566-670.

2. Summers GEJ, Hocking MP. Preoperative and postoperative motility disorders of the stomach. Surg Clin North Am. 1992;72(2):467-486.

3. Behrns KE, Sarr MG. Diagnosis and management of gastric emptying disorders. Adv Surg. 1994;27:233-255.

4. Gertler R, Rosenberg R, Feith M, Schuster T, Friess H. Pouch vs no pouch following total gastrectomy: meta-analysis and systematic review. Am J Gastroenterol. 2009;104(11):2838-2851.

5. Tomita R, Fujisaki S, Tanjoh K. Pathophysiological studies on the relationship between postgastrectomy syndrome and gastric emptying function at 5 years after pylorus-preserving distal gastrectomy for early gastric cancer. World J Surg. 2003;27(6):725-733.

6. Nakane Y, Akehira K, Inoue K, et al. Postoperative evaluation of pyloruspreserving gastrectomy for early gastric cancer. Hepatogastroenterology. 2000;47(32):590-595.

7. Yang YS, Chen LQ, Yan XX, Liu YL. Preservation versus nonpreservation of the duodenal passage following total gastrectomy: a systematic review. J Gastrointest Surg. 2013;17(5):877-886.

8. Abell TL, Camilleri M, Donohoe K, et al. Consensus recommendations for gastric emptying scintigraphy: a joint report of the American Neurogastroenterology and Motility Society and the Society of Nuclear Medicine. Am J Gastroenterol. 2008;103:753-763.

9. Donohoe KJ, Maurer AH, Ziessman HA, Urban JLC, Royal HD, MartinComin J; Society for Nuclear Medicine. Procedure guideline for adult solid-meal gastric-emptying study 3.0. J Nucl Med Technol. 2009; 37(3):196-200.

10. Mariani G, Boni G, Barreca M, et al. Radionuclide gastroesophageal motor studies. J Nucl Med. 2004;45(6):1004-1028.

OncoTargets and Therapy

\section{Publish your work in this journal}

OncoTargets and Therapy is an international, peer-reviewed, open access journal focusing on the pathological basis of all cancers, potential targets for therapy and treatment protocols employed to improve the management of cancer patients. The journal also focuses on the impact of management programs and new therapeutic agents and protocols on

Submit your manuscript here: http://www.dovepress.com/oncotargets-and-therapy-journal
11. Stanghellini V, Tosetti C, Corinaldesi R. Standards for non-invasive methods for gastrointestinal motility: scintigraphy - a position statement from the Gruppo Italiano di Studio Motilita Apparato Digerente (GISMSAD). Digest Liver Dis. 2000;32:447-452.

12. Michiura T, Nakane Y, Kanbara T. Assessment of the preserved function of the remnant stomach in pylorus-preserving gastrectomy by gastric emptying scintigraphy. World J Surg. 2006;30(7):1277-1283.

13. Eypasch E, Williams JI, Wood-Dauphinee S, et al. Gastrointestinal quality of life index: development, validation and application of a new instrument. Br J Surg. 1995;82(2):216-222.

14. Jung HJ, Lee JH, Ryu KW, et al. The influence of reconstruction methods on food retention phenomenon in the remnant stomach after a subtotal gastrectomy. J Surg Oncol. 2008;98(1):11-14.

15. Kang Y, Wei YZ, Xue YW. Meta-analysis on comparison of longterm complications and quality of life between two digestive tract reconstruction techniques following total gastrectomy. Zhonghua Wei Chang Wai Ke Za Zhi. 2013;16(2):135-139.

16. Schlatter C. Further observations on a case of total extirpation of the stomach in the human subject. Lancet. 1898;152(3925):1314.

17. Haberer G, Teichmann RK, Kramling HJ. Results of gastric resection for carcinoma of the stomach: the European experience. World J Surg. 1988; 12(3):374-381.

18. Hasler WL. The physiology of gastric motility and gastric emptying. In: Yamada T, Hasler WL, Alpers DH, Owyang C, Powell DW, Silverstein FE, editors. Textbook of Gastroenterology. 2nd ed. Philadelphia, PA: Lippincott; 1995:181-206.

19. Tomita R, Fujisaki S, Tanjoh K, Fukuzawa M. Studies on gastrointestinal hormone and jejunal interdigestive migrating motor complex in patients with or without early dumping syndrome after total gastrectomy with Roux-en-Y reconstruction for early gastric cancer. Am J Surg. 2003; 185(4):354-359.

20. Mochiki E, Kamiyama Y, Aihara R, et al. Postoperative functional evaluation of jejunal interposition with or without a pouch after a total gastrectomy for gastric cancer. Am J Surg. 2004;187(6):728-735.

21. Nakane Y, Akehira K, Okumura S, Okanuta S, Osada T, Okusa T. Emptying of the jejunal pouch as a gastric substitute after total gastrectomy for cancer. Hepatogastroenterology. 1997;44(15):901-906.

22. Griffith GH, Owen GM, Kirkman S, Shields R. Measurement of rate of gastric emptying using chromium-51. Lancet. 1966;1:1244-1245.

23. Miholic J, Meyer HJ, Kotzerke J, et al. Emptying of the gastric substitute after total gastrectomy. Ann Surg. 1989;210(2):165-172.

24. Wingate DL. Small intestine. In: Shuster MM, editor. Atlas of Gastrointestinal Motility in Health and Disease. Baltimore: Williams and Wilkins; 1993:177-214.

25. Koch KL. Diagnosis and treatment of neuromuscular disorders of the stomach. Curr Gastroenterol Rep. 2003;5(4):323-330.

26. Sarr MG, Kelly KA. Myoelectric activity of the autotransplanted canine jejunoileum. Gastroenterology. 1981;81(2):303-310.

27. Tsujimoto H, Sakamoto N, Ichikur T, et al. Optimal size of jejunal pouch as a reservoir after total gastrectomy: a single-center prospective randomized study. J Gastrointest Surg. 2011;15(10):1777-1782.

patient perspectives such as quality of life, adherence and satisfaction. The manuscript management system is completely online and includes a very quick and fair peer-review system, which is all easy to use. Visit http://www.dovepress.com/testimonials.php to read real quotes from published authors.

\section{Dovepress}

